\title{
Full Scale Experiments for Determining the Burning Conditions to Be Applied to Toxicity Tests
}

\author{
TAKEYOSHI TANAKA, ICHIRO NAKAYA, and MASASHI YOSHIDA \\ Building Research Institute \\ Ministry of Construction \\ Japan
}

ABSTRACT:

A series of full scale steady state fire experiments were conducted with a propane burner as the fire source in an attempt to determine the thermal and atmospheric conditions to which building materials are likely to be subjected in the event of a building fire. As a result of the experiments, a close coupling was revealed between the temperature elevation and the oxygen depletion in the room of origin. Based on this finding and the results of other experiments with a crib fire source, some thoughts are presented on the burning conditions to be applied to toxicity test apparatus.

\section{INTRODUCTION}

Since many kinds of artificial materials have recently entered our daily lives as building materials and furnishings etc., various test methods have been developed in many countries to discover and target for removal of those new materials that may cause extremely toxic hazard in the event of fire. Toxicity is a problem, however, so sensitive and complicated that, so far, little has been agreed among the people concerned with test methods how the evaluation of toxicity should be accomplished. Consequently, toxicity test methods which have been proposed differ in many ways. This inevitably causes discrepancies in evaluation even for the same material.

The U.S.A-Canada-Japan cooperative research on toxicity was, to a large extent, motivated by such conditions related to the current toxicity test methods. This study is, as a part of this toxicity project, intended to determine the conditions under which materials should be burned in a toxicity test. The most important factors that affect the burning behavior of materials and the production of toxicants are thought to be the thermal conditions imposed on the materials, and the atmospheric enviromment in which pyrolyzed volatiles from the materials undergo combustion. Therefore, the temperature, the heat transfer and the oxygen concentration in the room of origin were investigated in this study.

\section{THE EXPERIMENT}

At present, the most reliable way to approach the behavior of real fire is considered to be full scale fire experiments. However, a large number of 
full scale experiments can hardly be carried out in view of expense and 1abor. In order to get the best results from the limited number of full scale experiments available, it will be desirable to have insight on the basic relationship between fire behavior and the conditions that control the fire behavior before many tests are conducted. For this reason, a series of full scale tests were conducted with a propane gas burner as the fire source, since it is beneficial for various analyses to use a simple fuel whose properties are well known.

\section{Experimenta1 Apparatus}

The test apparatus employed for this series of experiments is, as illustrated in Fig.1, composed of a burn room, whose interior surfaces are lined with calcium silicate boards, and an adjacent room.

\section{Measurements}

Room temperatures - As shown in Fig.1, three thermocouple trees, one in the room of origin and the other two in the adjacent room, were used for the temperature profiles in the rooms, and on each tree 20 suction thermocouples were located at every $10 \mathrm{~cm}$ spacing from the floor.
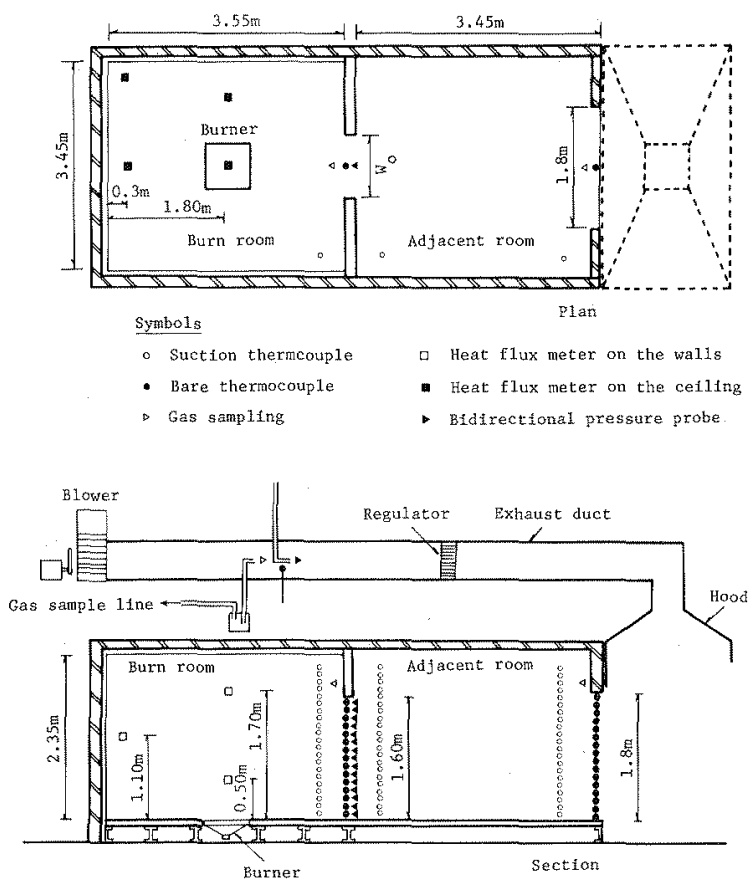

FIGURE 1. Experimental apparatus and instrumentation 
Opening temperatures - Bare thermocouples, whose heights are the same as those of the suction thermocouples for room temperature, were used for the opening flow temperature measurement.

Opening flow pressure - Bidirectional pressure probes located at every $10 \mathrm{~cm}$ of height were used to measure the doorway flow pressure and to produce the doorway flow rate together with the temperature measurement.

Heat transfer - Six total heat flow meters, Hycal mode1 C-1300A, three of which were mounted on the ceiling and the other three on the walls, were used for heat transfer to the room surfaces.

Gas concentrations - The gas were sampled from a point right above the doorway, inside the burn room, and analyzed for $\mathrm{O}_{2}, \mathrm{CO}_{2}$ and $\mathrm{CO}$ concentrations.

\section{Test Conditions}

The measurements were started after warming up the burn room for $20-40$ minutes to attain a steady state condition of fire and continued for 2-4 hours. The tests were conducted for the following opening widths and fuel input rates: Opening width $\quad-89,59,45,29$ (cm)

Propane gas input $-50,100,150,200,250,300,350(\ell / \mathrm{min})$

\section{EXPERIMENTAL RESULTS}

Temperature Profile in the Room of Origin

The temperature profiles in the burn room, which are exemplified in Fig. 2 for $59 \mathrm{~cm}$ and $29 \mathrm{~cm}$ of doorway widths, demonstrate that the upper layer is fairly uniform in temperature and gets thicker as the doorway width gets narrower.

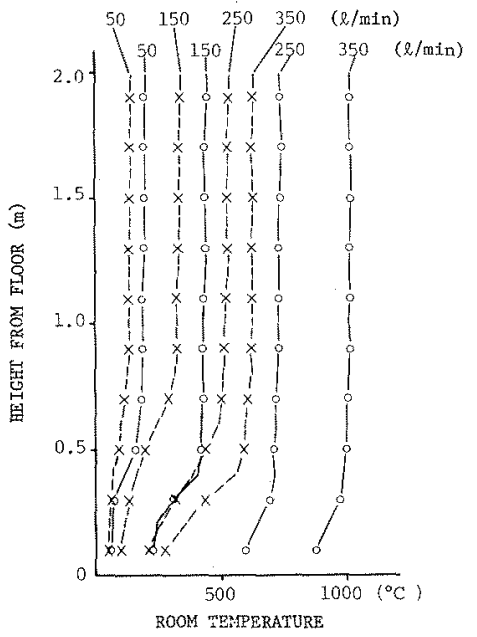

$-x--59 \mathrm{~cm}-0-29 \mathrm{~cm}$

FIGURE 2. Temperature profile in the burn room

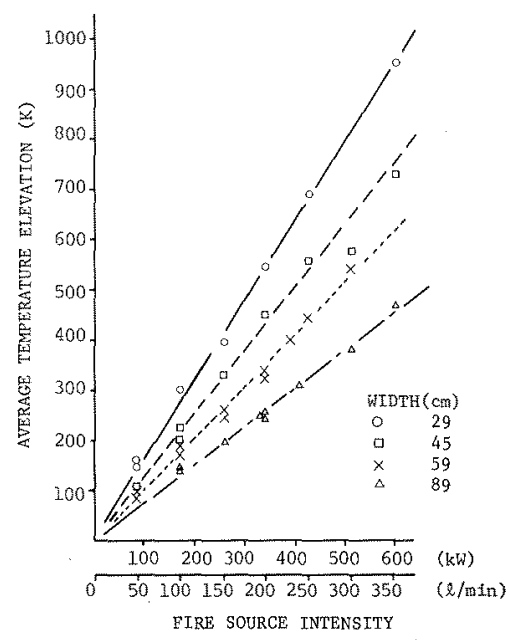

FIGURE 3. Burn room temperature rise and fire source intensity 


\section{Fire Source Intensity - Temperature Elevation}

In this series of experiments, a proportional relationship was found between the fire source intensity (fuel input rate) and the average temperature elevation of the room of origin for each opening width as shown in Fig. 3 . It is suspected that longer warming up of the room could have brought more perfect linear relationship between the two.

\section{Doorway Flow Rate}

The symbols in Fig. 4 exhibit the flow rates through the opening, which were obtained by reducing the measured data in the same manner as Steckler's(2) and were plotted versus the average fire room temperature. It is observed in this figure that temperature dependence of the doorway flow rates is not significant for the region where temperature is above $200-300{ }^{\circ} \mathrm{C}$. If we estimate doorway flow by a simple model based on uniform room temperature as sumption, we obtain:

$$
\mathrm{m}_{\mathrm{d}}=\frac{2}{3} \alpha B \mathrm{H}^{3 / 2} \sqrt{2 \mathrm{~g} \rho} \frac{\left(1-\frac{\mathrm{T}}{\mathrm{T}}\right)^{1 / 2}}{\left\{1+\left(\frac{\mathrm{T}_{\mathrm{G}}}{\mathrm{T}_{\mathrm{a}}}\right)^{1 / 3}\right\}^{3 / 2}}
$$

The calculated results of Eq.(1) are shown also in Fig.4 by solid lines, by which the same tendency can be recognized in the dependence of the doorway flow rates on temperature. The reason why the discrepancy between the experimentally obtained flow rates and the theoretical estimation becomes larger as the doorway width gets wider may be attributed to the fact that in the case of the wide doorway, the burn room is stratified into two layers and so the single uniform temperature assumption no longer holds.

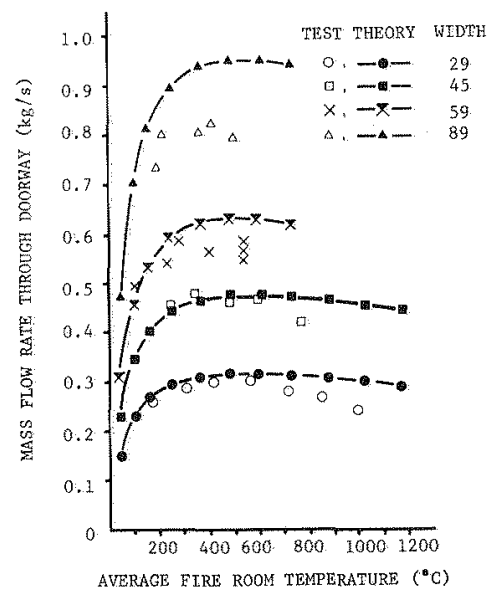

FIGURE 4. The doorway mass flow rate

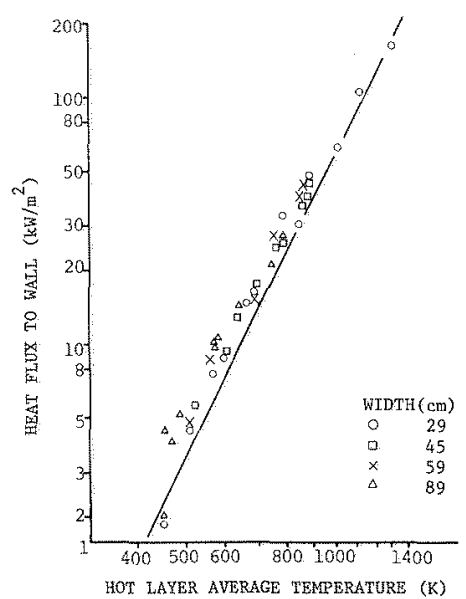

FIGURE 5. The heat flux to wall surface 
Average heat fluxes to the walls are plotted in Fig.5 versus the temperatures averaged over what seemed to be the upper layers of the burn room There was no significant difference among the heat fluxes measured by the six heat flux meters on each location of the ceiling and the walls. Since the measurements were made using water cooled total heat flux meters, the heat fluxes shown here are considered to be almost the total incident heat fluxes to the walls. The solid line in this figure represents the theoretical radiant heat flux that the room gas would emit if it were black. The measured heat flux data almost always lie above this 1ine. In most cases, the real fire gas will be close to black due to a significant amount of smoke particles involved but in this series of experiments, in which propane was the fuel used, it is not evident whether or not the fire room gas can be regarded as black, although a significant amount of soot production was observed. If the emissivity of the gas is small, the influence of wall surface temperature will appear in the incident heat flux to the wal1. For instance, in the case of a room with uniform interior surface temperature filled with homogeneous gas, the incident heat flux $\mathrm{q}^{\prime \prime}$ is:

$\mathrm{q}^{\prime \prime}=\varepsilon_{\mathrm{G}} \sigma \mathrm{T}_{\mathrm{G}}^{4}+\left(1-\varepsilon_{\mathrm{G}}\right) \varepsilon_{\mathrm{W}} \sigma \mathrm{T}_{\mathrm{W}}^{4}$

where $\varepsilon_{G}$ and $\varepsilon_{W}$ are the emissivities of the room gas and the interior surface, respectively, and $\mathrm{T}_{\mathrm{G}}$ and $\mathrm{T}_{\mathrm{W}}$ are the gas and the interior surface temperatures. In the present experiments, the incident heat flux was almost as large as the theoretical black gas radiation either because the gas was sooty enough to be approximately black or because the wall surface temperature was as high as the room gas temperature due to its high insulation performance.

\section{Gas Concentration and Observation}

In the experiments, the fire room gas was analyzed for $\mathrm{O}_{2}, \mathrm{CO}_{2}$ and $\mathrm{CO}$, but the concentration of co was negligibly low in every case, probably because fire sizes were still too small to bring incomplete combustion even in the case of the narrowest opening.

Flames were not observed to come out of the burn room in any test although they seemed to extend and fill the room in the case of $29 \mathrm{~cm}$ doorway width with $300 \mathrm{\ell} / \mathrm{min}$ and $350 \mathrm{\ell} / \mathrm{min}$ of fuel input.

\section{DISCUSSIONS}

\section{Heat Transfer}

If we look at the heat conservation in the room of origin in a steady state condition, we will have the following general equation:

$Q_{f}=Q_{d}+Q_{d r}+Q_{W}$

where $Q_{f}$ is the heat released in the room of origin, $Q_{d}, Q_{d r}$, and $Q_{w}$ are the heat losses due to opening flow, radiation through the opening and heat transfer to the wall, respectively. It will be interesting to investigate the contribution of each mode of heat loss in the total heat. The results shown in Fig. 6 are the convective heat losses through the doorway in the tests estimated 
by the following equation:

$Q_{d}=C_{p} m_{d}\left(T_{G}-T_{a}\right)$

where $C$ is the specific heat of $g$ as and $T_{C}$ is the average temperature of the room gas. It can be seen in Fig.6 that the heat loss due to the doorway convection is almost proportional to the fire source intensity, and is about $50 \%$ of the heat released in the room. The solid line drawn for reference in Fig. 6 represents $50 \%$ of the heat input. The fraction of the heat loss due to convection tends to increase slightly as the doorway width becomes wider but the inclination is not so conspicuous. As was already shown in Figs.3 and 4, the room temperature elevation $T_{-}-T_{\text {a }}$ becomes smaller, while the doorway mass flow rate becomes larger, with the increase of the doorway width. This means that the former counterbalances the latter and thus convective heat loss through doorway turns out to be less dependent on doorway width. Once the convective heat loss due to doorway flow is known, the net heat transfer to the wall can be estimated.

Temperature Elevation and Oxygen Depletion in the Present Experiments

If combustion in the room of origin is vigorous, the room temperature inevitably gets high. At the same time, the oxygen concentration in the room must be low because vigorous combustion consumes a large amount of oxygen in the room. When a room has a large opening, in other words when the ventilation rate is large, the oxygen depletion in the room will be comparatively small and the temperature elevation. must be small too because of the large amount of air that flows into the room and needs be heated up. Thus a strong relationship is suspected to exist between the temperature elevation and the oxygen depletion in the room of origin.

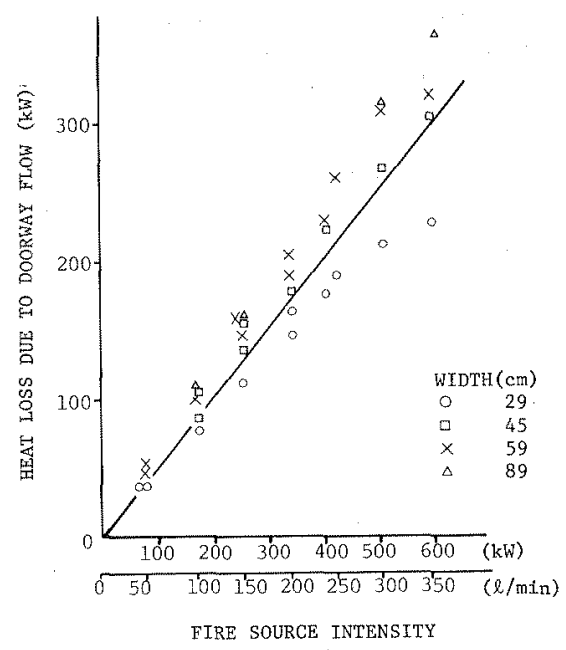

FIGURE 6. The fraction of the heat loss due to the doorway flow to the total heat release 
In the above, it was seen that the fraction of convective heat loss associated with the opening flow to the total heat release( $\equiv k$ ) was nearly constant in this series of experiments, that is:

$\mathrm{Q}_{\mathrm{d}}=\mathrm{k} \mathrm{Q}_{\mathrm{f}}$

Noting that heat of combustion per unit of oxygen consumed is almost constant over a wide variety of fuels(3), $Q_{f}$ can be conveniently written as

$\mathrm{Q}_{\mathrm{f}}=\mathrm{E} \Delta \mathrm{x}_{\mathrm{O}_{2}} \frac{\mathrm{m}_{\mathrm{d}}}{\mathrm{W}_{\mathrm{air}}}$

where $\Delta \mathrm{X}_{\mathrm{O}_{2}}$ is the difference of oxygen mole fraction between inflow air and outflow gas $\left(=0.21-\mathrm{X}_{\mathrm{O}_{2}}\right), \mathrm{E}$ is the heat of combustion of fuel per unit mole of oxygen consumed, and $W_{\text {air }}$ denotes the molecular weight of air. On the other hand $Q_{d}$ can be written as

$\mathrm{Q}_{\mathrm{d}}=\mathrm{C}_{\mathrm{p}} \mathrm{m}_{\mathrm{d}} \Delta \mathrm{T}$

where $\Delta \mathrm{T}$ is the room temperature elevation $\left(=\mathrm{T}_{\mathrm{G}}-\mathrm{T}_{\mathrm{a}}\right)$. From Eqs. (6) and. (7),

$\Delta \mathrm{T}=\frac{\mathrm{k} \cdot \mathrm{E}}{\mathrm{C}_{\mathrm{p}} \mathrm{W} \text { air }} \Delta \mathrm{x}_{\mathrm{O}_{2}}$

Equation (8) indicates that the temperature elevation should be proportional to the oxygen depletion and independent of the doorway flow rate. If 0.5 is taken for the value of $\mathrm{k}, \mathrm{Eq} .(8)$ turns out to be as follows:

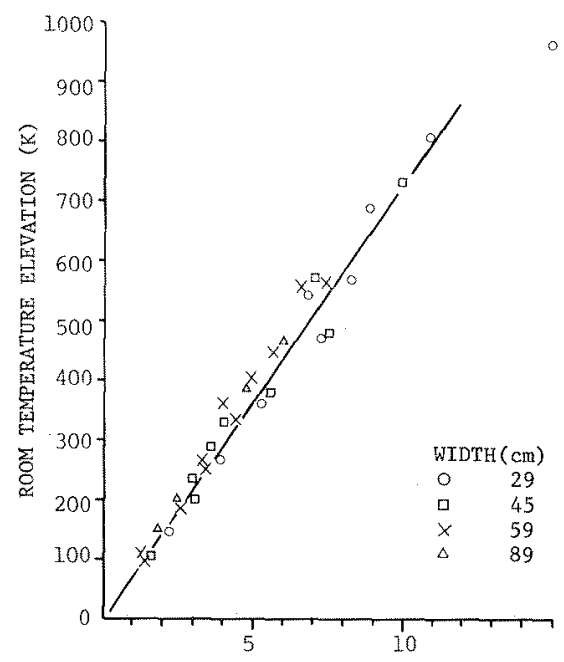

OXYGEN CONCENTRATION DECREASE (\%)

FIGURE 7. The temperature rise and the oxygen concentration decrease in the burn room 
$\Delta \mathrm{T}=\frac{\mathrm{k} \cdot \mathrm{E}}{\mathrm{C}_{\mathrm{p}} \mathrm{W}_{\mathrm{air}}} \Delta \mathrm{x}_{\mathrm{O}_{2}}=\frac{0.5 \times 410}{1.0 \times 0.029} \Delta \mathrm{x}_{\mathrm{O}_{2}}=7,069 \Delta \mathrm{x}_{\mathrm{O}_{2}}$

This indicates that the temperature elevation rate will be about $70 \mathrm{~K}$ per $1 \%$ of the oxygen concentration decrease. With this in mind, the test data were plotted in Fig.7. It can be seen that this prediction nearly holds at least for small oxygen depletion. It is not obvious if this relationship remain valid for a larger decrease in the oxygen concentration. If this holds, then it follows that the temperature elevation cannot exceed about $1,500 \mathrm{~K}$ because oxygen concentration decrease must be less than 0.21 .

Theoretically, the rate of temperature elevation per unit oxygen concentration decrease must depend on the level of thermal insulation performance of the room. For example, if the room is perfectly adiabatic, all the heat released by fire must be convected out of the room only by the doorway flow, which means $\mathrm{k}$ in $\mathrm{Eq}$. (8) must be unity and the temperature elevation rate will be about $140 \mathrm{k}$. However, rooms are usually not insulated so perfectly. Therefore, it is 1ikely that in a normal room fire, the temperature elevation rate is less than those of the present tests because the burn room employed in this series of experiments was not very large in size and was lined with calcium silicate boards, whose thermal insulation performance is among the highests of many construction materials.

\section{Temperature Elevation - Oxygen Depletion in General Cases}

As was demonstrated in Fig.7, an almost 1inear relationship was obtained between the temperature elevation and the oxygen concentration decrease for the steady state fire. However, it is not guaranteed that this relationship always holds since the results were only from limited test conditions. In different thermal or ventilation conditions or in nonsteady state conditions, the results may be different. In Fig.8, the data were taken from the crib fire experiments which were conducted while using the same apparatus and from other literatures $(4,5)$ for the peak burning period and they wexe plotted together with the present test data. According to the data in Fig.8, the temperature elevation rates tend to scatter over a somewhat wider region than in the steady state case, but still appear to stay within a limited range covered by a narrow angle that has the origin of the coordinates as the apex.

If a room of origin filled with a single homogeneous gas layer is taken as a simple example, an approximate equation for the heat balance in the room can be given as follows:

$\mathrm{E} \frac{\mathrm{m}_{\mathrm{d}}}{\mathrm{W}_{\text {air }}} \Delta \mathrm{X}_{2}=\mathrm{C}_{\mathrm{p}} \mathrm{m}_{\mathrm{d}}\left(\mathrm{T}_{\mathrm{G}}-\mathrm{T}_{\mathrm{a}}\right)+\mathrm{A}_{\mathrm{W}}\left\{\sigma\left(\mathrm{T}_{\mathrm{G}}^{4}-\mathrm{T}_{\mathrm{W}}^{4}\right)+\mathrm{h}_{\mathrm{c}}\left(\mathrm{T}_{\mathrm{G}}-\mathrm{T}_{\mathrm{W}}\right)\right\}$

heat release convective loss heat loss to walls

where the radiation loss to the outside through the opening is neglected, the emissivities of the gas and the wall are assumed as unity, and inflow and outflow rates are assumed the same. When the wall is a good thermal insulator and small in area, the heat loss to the wall is small. In the case of a perfect thermal insulator, as was seen previously, it follows that $\Delta \mathrm{T}=14,000 \Delta \mathrm{x}_{\mathrm{O}_{2}}$. In an actual fire, however, $\Delta \mathrm{T}=7,000 \Delta \mathrm{X}_{\mathrm{O}_{2}}$ will virtually give the maximum temperature elevation rate attainable per unit oxygen concentration decrease by the reason given in the above. 
On the other hand, it is much more difficult to determine the lowest limit of the temperature elevation rate. If we suppose a case in which the thermal conductivity of the room wall is extremely large, as large as metals for example, Eq.(10) can be reduced to

$\frac{\mathrm{E}(\mathrm{cA} \sqrt{\mathrm{H}})}{\mathrm{W}_{\text {air }}} \Delta \mathrm{X}_{\mathrm{O}_{2}}=\mathrm{C}_{\mathrm{p}}(\mathrm{cA} \sqrt{\mathrm{H}}) \Delta \mathrm{T}+\frac{\mathrm{A}_{\mathrm{W}}}{2}\left(\sigma\left(\mathrm{T}_{\mathrm{G}}^{4}-\mathrm{T}_{\mathrm{a}}^{4}\right)+\mathrm{h}_{\mathrm{c}} \Delta \mathrm{T}\right\}$

where an attention was paid of the fact that doorway flow rate $m_{d}$ does not greatly vary with room temperature and hence can be determined almost only by $A \sqrt{I}$ of the doorway. Equation (11) shows that the temperature elevation rate still depends on wall area and opening dimensions even in the simplest case. It will be beneficial to use some mathematical modeling techniques for determining the lowest limit of temperature elevations, since so many experiments cannot be conducted using an apparatus with a large wall area.

From the empirical relationship between heat release rate and temperature rise that was discovered by Mccaffrey and Quintiere(6), it is implied that temperature rise $\Delta \mathrm{T}$ varies proportionally to $\Delta \mathrm{X}_{\mathrm{O}_{2}}^{2 / 3}$ rather than to $\Delta \mathrm{X}_{2}$ (7). The data in Fig.8 do seem to support their prediction but we would like to refrain from any hasty conclusion and only value the empirical findings until we reach to a deeper understanding of the mechanism that bring this relationship between temperature elevation and oxygen concentration depletion.

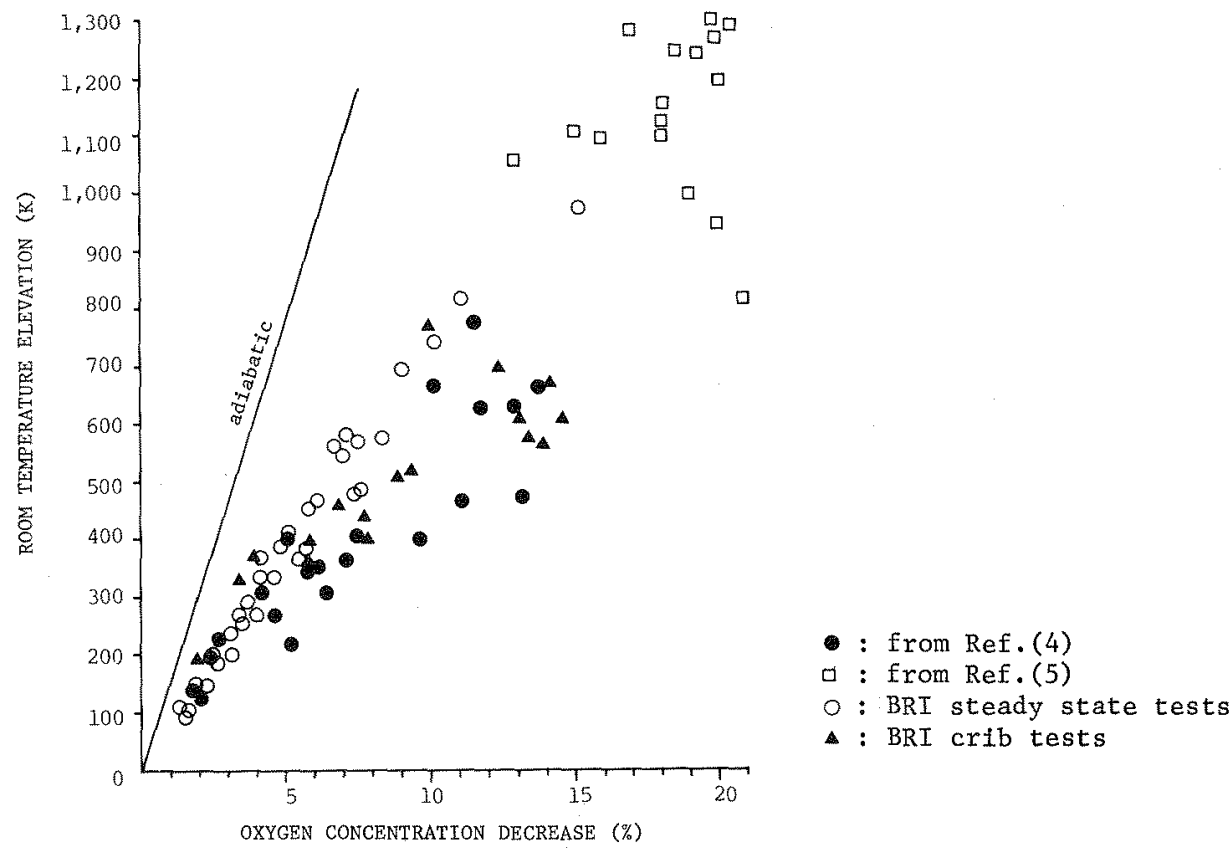

FIGURE 8. The relationship between the temperature rise and the oxygen concentration decrease in general case (peak values) 


\section{CONCLUDING REMARKS}

When we discuss the issues concerning a toxicity testing of building materials, etc. It will be the important to identify in what scenarios will the toxicity due to the burning of materials become a serious problem. And then the fire conditions that correspond to these scenarios need to be clarified. It will be reasonable to think that the conditions in developing or fully developed stage of fire which continue for a considerable time period are more important than a transient short time condition in view of the influence on people's evacuation.

In this series of steady state fire experiments, it was demonstrated that, in the room of origin, the heat transfer to the ceiling and the upper part of the walls maintain a considerable homogenuity, and a strong correlation exists between the temperature elevation and the oxygen concentration. The latter, of course, means a strong relation between the incident heat flux to the materials on the room interior surfaces and the oxygen concentration in the room, to which pyrolyzed volatiles come out, since a room temperature and the incident heat flux to the room boundaries are almost in one to one correspondence. This finding on the thermal and atmospheric conditions in the room of origin is not enough to pinpoint the conditions to be applied to a toxicity test apparatus. The conditions that are conceivable in fire at various stages still range over wide area. However, it can be said that this finding did narrow the conditions that must be considered in testing materials and will help remove the test conditions are unreasonable that in view of realistic fire situations.

\section{ACKNOWLEDGEMENT}

The authors would like to thank Dr. Quintiere, Center for Fire Research, NBS, for his informative comments on our study and fruitful discussions with us during his technical visit to Japan in October 1984.

\section{REFERENCES}

1. Bukowski,R.W., Jones,W.W. "Development of a Method for Assessing Toxic Hazard", 3rd Expert Meeting of Canada-Japan-U.S.A Cooperative Study on Toxicity, NRC Canada, October 1984.

2. Steckler,K.D., Quintiere,J.G. and Rinkienen,W.J. "Flow Induced by Fire in a Compartment", NBSIR 82-2520, 1982.

3. Hugget,C. "Estimation of Rate of Heat Release by Means of oxygen Consumption Measurements", Fire and Materials. Vol 4. No2. 1980.

4. Quintiere,J.G.,McCaffrey,B.J. "The Burning of Wood and Plastic Crib in an Enclosure: Volume $1^{\prime \prime}$, NBSTR 80-2054, November 1980.

5. Bohm, B. "Fully Developed Polyethylene and Wood Compartment Fires with Application to Structual Design", Technical Univ. of Denmark, 1977.

6. Quintiere,J.Q. "A Simple Correlation for Predicting Temperature in a Room Fire", NBSIR 83-2712, June 1983.

7. Personal communication with Dr. Quintiere. 